\title{
How We Think: A Theory of Human Decision-Making, with a Focus on Teaching
}

\author{
Alan H. Schoenfeld
}

\begin{abstract}
Suppose a person is engaged in a complex activity, such as teaching. What determines what that person does, on a moment-by-moment basis, as he or she engages in that activity? What resources does the person draw upon, and why? What shapes the choices the person makes? I claim that if you know enough about a teacher's knowledge, goals, and beliefs, you can explain every decision he or she makes, in the midst of teaching. In this paper I give examples showing what shapes teachers' decision-making, and explain the theory.
\end{abstract}

Keywords Decision-making • Teaching • Theory

\section{Introduction}

I became a mathematician for the simple reason that I love mathematics. Doing mathematics can be a source of great pleasure: when you come to understand it, the subject fits together beautifully. Here I am not necessarily referring to advanced mathematics. The child who notices that every time she adds two odd numbers the result is even, wonders why, and the figures out the reason why:

Each odd number is made up of a number of pairs, and one 'extra.' When you add two odd numbers together, the extras make a pair. That means that the sum is made up of pairs, so it's even!

is doing real mathematics. It was that kind of experience that led me into mathematics in the first place.

Sadly, very few people develop this kind of understanding, or this kind of pleasure in doing mathematics. It was this realization, and the thought that it might be possible to do something to change it, that led me into mathematics education.

\footnotetext{
A.H. Schoenfeld ( $\square)$

University of California at Berkeley, Berkeley, CA, USA

e-mail: alans@berkeley.edu

(C) The Author(s) 2015

S.J. Cho (ed.), The Proceedings of the 12th International Congress

on Mathematical Education, DOI 10.1007/978-3-319-12688-3_16
} 
For more than 35 years I have pursued the question, "How can we develop deeper understandings of mathematical thinking, problem solving, and teaching, so that we can help more children experience the pleasures of doing mathematics?"

My early work was devoted to mathematical problem solving. I read Pólya's (1945) book How to Solve It early in my mathematical career, and it resonated. Pólya said that mathematicians used a wide range of problem solving strategies, which he called heuristics. When he described them, I recognized them-I used them too! I wondered, though, why I had not explicitly been taught those strategies. The answer, I learned, was that when people tried to teach the strategies described in Pólya's books, students did not learn to use them effectively. This was disappointing, but it also represented a lovely challenge. Could we understand such problem solving strategies well enough so that we could help students learn to use them effectively?

Thus began a decade's worth of work in which I tried to develop an understanding of problem solving: What do effective problem solvers do, which enables them to solve difficult problems? What do ineffective problem solvers do, that causes them to fail in their problem solving attempts? What can we do, as teachers, to help students become more effective problem solvers? My answers to those questions, which are summarized very briefly below, were published in my 1985 book Mathematical Problem Solving. The book resulted from a decade of simultaneous research on and teaching of problem solving, in which my theoretical ideas were tried in the classroom, and my experience in the classroom gave rise to more theoretical ideas.

Mathematical Problem Solving represented a solid first step in a research agenda. By the time it was written, I knew enough about problem solving to help students become more effective problem solvers. A next, logical goal was to help mathematics teachers to help their students develop deeper understandings of mathematics. In many ways, of course, teaching is an act of problem solving - but it is so much more. The challenge was, could I develop a theoretical understanding of teaching in ways that allowed me to understand how and why teachers make the choices they do, as they teach? Could that understanding then be used to help teachers become more effective? Moreover, to the degree that teaching is typical of knowledge-intensive decision making, could the theoretical descriptions of teaching be used to characterize decision making in other areas as well?

Those questions have been at the core of my research agenda for the past 25 years. My answers to them now exist, in a new book, How We Think (Schoenfeld 2010). The purpose of this paper is to illustrate and explain the main ideas in the book. Because my current research has evolved from my earlier problem solving work, I set the stage for the discussion that follows with a brief description of that work - what it showed and, more importantly, the questions that it did not answer. That will allow me to describe what a complete theory should be able to accomplish. I then turn to the main body of this paper, three studies of teaching. In those examples I show how, under certain circumstances, it is possible to model the act of teaching, to the point where one can provide a grounded explanation of every decision that a teacher makes during an extended episode of teaching. Following that, I give some other examples to suggest that the theory is general, and I make a few concluding comments. 


\section{The Challenge}

Suppose that you are in the middle of some "well practiced" activity, something you have done often so that it is familiar to you. Depending on who you are, it might be

- cooking a meal

- fixing a car

- teaching a class

- doing medical diagnosis or brain surgery.

The challenge is this: If I know "enough" about you, can I explain (i.e., build a cognitive model that explains) every single action you take and every decision you make?

My goal for this paper is to describe an analytic structure that does just that - an analytic structure that explains how and why people act the way they do, on a momentby-moment basis, in the midst of complex, often social activities such as teaching.

My major claim is this: People's in-the-moment decision making when they teach, and when they engage in other well practiced, knowledge intensive activities, is a function of their knowledge and resources, goals, and beliefs and orientations. Their decisions and actions can be "captured" (explained and modeled) in detail using only these constructs.

The main substance of this paper (as in the book) consists of three analyses of teaching, to convey the flavor of the work. Of course, it is no accident that I chose mathematics teaching as the focal area for my analyses. I am, after all, a mathematics educator! But more to the point, teaching is a knowledge intensive, highly interactive, dynamic activity. If it is possible to validate a theory that explains teachers' decision making in a wide range of circumstances, then that theory should serve to explain all well practiced behavior.

\section{Background: Problem Solving}

As discussed above, my current work is an outgrowth of my earlier research on mathematical problem solving. Here I want to summarize the core findings of that work, to show how it lays the groundwork for my current research.

My major argument about mathematical problem solving (see Schoenfeld 1985, for detail) was that it is possible to explain someone's success or failure in trying to solve problems on the basis of the following four things:

1. Knowledge (or more broadly, resources). This is not exactly shocking-but, knowing what knowledge and resources a problem solver has potentially at his or her disposal is important.

2. Problem solving strategies, also known as "heuristics." We know from Pólya's work that mathematicians use heuristic strategies, "rules of thumb for making 
progress when you do not know a direct way to a solution." Faculty pick up these strategies by themselves, through experience. Typically, students don't use them. But, my research showed that students can learn to use them.

3. "Metacognition," or "Monitoring and self-regulation." Effective problem solvers plan, and they keep track of how well things are going as they implement their plans. If they seem to be making progress, they continue; if there are difficulties, they re-evaluate and consider alternatives. Ineffective problem solvers (including most students) do not do this. As a result, they can fail to solve problems that they could solve. Students can learn to be more effective at these kinds of behaviors.

4. Beliefs. Students' beliefs about themselves and the nature of the mathematical enterprise, derived from their experiences with mathematics, shape the knowledge they draw upon during problem solving and the ways they do or do not use that knowledge. For example, students who believe that "all problems can be solved in 5 min or less" will stop working on problems even though, had they persevered, they might have solved them. Students who believe that "proof has nothing to do with discovery or invention" will, in the context of "discovery" problems, make conjectures that contradict results they have just proven. (see Schoenfeld 1985).

In sum: By 1985 we know what "counted" in mathematical problem solving, in the sense that we could explain, post hoc, what accounted for success or failure. As the ensuing 25 years have shown, this applied to all "goal-oriented" or problem solving domains, including mathematics, physics, electronic trouble-shooting, and writing.

BUT... There was a lot that the framework that I have just described did not do. In the research I conducted for Mathematical Problem Solving, people worked in isolation on problems that I gave them to solve. Thus: the goals were established (i.e., "solve this problem"); the tasks didn't change while people worked on them; and social interactions and considerations were negligible.

In addition, Mathematical Problem Solving offered a framework, not a theory. Above and beyond pointing out what is important-which is what a framework does - a theory should provide rigorous explanations of how and why things fit together. That is what my current work is about. What I have been working on for the past 25 years is a theoretical approach that explains how and why people make the choices they do, while working on issues they care about and have some experience with, amidst dynamically changing social environments.

I can think of no better domain to study than teaching. Teaching is knowledge intensive. It calls for instant decision making in a dynamically changing environment. It's highly social. And, if you can model teaching, you can model just about anything! I will argue that if you can model teaching, you can model: shopping; preparing a meal; an ordinary day at work; automobile mechanics; brain surgery (or any other medical practice), and other comparably complex, "well practiced" behaviors. All of these activities involve goal-oriented behavior-drawing on available resources (not the least of which is knowledge) and making decisions in order to achieve outcomes you value. 
The goal of my work, and this paper, is to describe a theoretical architecture that explains people's decision-making during such activities.

\section{How Things Work}

My main theoretical claim is that goal-oriented "acting in the moment"-including problem solving, tutoring, teaching, cooking, and brain surgery — can be explained and modeled by a theoretical architecture in which the following are represented: Resources (especially knowledge); Goals; Orientations (an abstraction of beliefs, including values, preferences, etc.); and Decision-Making (which can be modeled as a form of subjective cost-benefit analysis). For substantiation, in excruciating detail, please see my book, How we Think. To briefly provide substantiation I will provide three examples in what follows. But first, a top-level view of how things work is given in Fig. 1. The basic structure is recursive: Individuals orient to situations and decide (on the basis of beliefs and available resources) how to pursue their goals. If the situation is familiar, they implement familiar routines; if things are

\section{How Things Work}

- An individual enters into a particular context with a specific body of resources, goals, and orientations.

- The individual takes in and orients to the situation. Certain pieces of information and knowledge become salient and are activated.

- Goals are established (or reinforced if they pre-existed).

- Decisions consistent with these goals are made, consciously or unconsciously, regarding what directions to pursue and what resources to use:

- If the situation is familiar, then the process may be relatively automatic, where the action(s) taken are in essence the access and implementation of scripts, frames, routines, or schemata.

- If the situation is not familiar or there is something non-routine about it, then decision-making is made by a mechanism that can be modeled by (i.e., is consistent with the results of) using the subjective expected values of available options, given the orientations of the individual.

- Implementation begins.

- Monitoring (whether it is effective or not) takes place on an ongoing basis.

- This process is iterative, down to the level of individual utterances or actions:

- Routines aimed at particular goals have sub-routines, which have their own subgoals;

- If a subgoal is satisfied, the individual proceeds to another goal or subgoal;

- If a goal is achieved, new goals kick in via decision-making;

- If the process is interrupted or things don't seem to be going well, decision-making kicks into action once again. This may or may not result in a change of goals and/or the pathways used to try to achieve them.

Fig. 1 How things work, in outline. From Schoenfeld (2010), p. 18, with permission 
unfamiliar or problematic, they reconsider. It may seem surprising, but if you know enough about an individual's resources, goals, and beliefs, this approach allows you to model their behavior (after a huge amount of work!) on a line-by-line basis.

\section{First Teaching Example, Mark Nelson}

Mark Nelson is a beginning teacher. In an elementary algebra class, Nelson has worked through problems like, $x^{5} / x^{3}=$ ? Now he has assigned

$$
\begin{array}{llll}
\text { (a) } m^{6} / m^{2}, & \text { (b) } x^{3} y^{7} / x^{2} y^{6}, & \text { and } & \text { (c) } x^{5} / x^{5}
\end{array}
$$

for the class to work. Nelson expects the students to have little trouble with $m^{6} / m^{2}$ and $x^{3} y^{7} / x^{2} y^{6}$, but to be "confused" about $x^{5} / x^{5}$; he plans to "work through" their confusion. Here is what happens.

Nelson calls on students to give answers to the first two examples. He has a straightforward method for doing so:

- He asks the students what they got for the answer, and confirms that it is correct.

- He asks how they got the answer.

- Then he elaborates on their responses.

Thus, for example, when a student says the answer to problem (b) is $x y$, Nelson asks "why did you get $x y$ ?" When the student says that he subtracted, Nelson asks, "What did you subtract? When the student says "3 minus 2," Nelson elaborates:

OK. You looked at the $x$ 's [pointing to $x$-terms in numerator and denominator] and [pointing to exponents] you subtracted 3 minus 2. That gave you $x$ to the first [writes $x$ on the board]. And then [points to y terms] you looked at the $y$ 's and said [points to the exponents] 7 minus 6 , gives you y to the first [writes y on board].

He then asks what to do with $x^{5} / x^{5}$. They expand and "cancel." The board shows $\frac{x+x \mid x x}{x x y x x}$

"zero," "zip," "nada," and "nothing" ... not what he wants them to see! He tries various ways to get the students to see that "cancelling" results in a "1", for example,

Nelson: "What's 5/5?"

Students: "1."

Nelson: "But I cancelled. If there's a 1 there [in 5/5], isn't there a 1 there [pointing to the cancelled expression]?"

Students: "No." 
Defeated, he slumps at the board while students argue there's "nothing there." He looks as if there is nothing he can say or do that will make sense to the students.

He tries again. He points to the expression $\frac{\operatorname{xx} x x x x}{x \times x \times x x}$ and asks what the answer is. A student says " $x$ to the zero over 1." Interestingly, Nelson mis-hears this as " $x$ to the zero equals 1," which is the correct answer. Relieved, he tells the class,

"That's right. Get this in your notes: $x^{5} / x^{5}=x^{0}=1 . "$

Any number to the zero power equals $1 . "$

To put things simply, this is very strange. Nelson certainly knew enough mathematics to be able to explain that if $\mathrm{x} \neq 0$,

$$
\left(\frac{x^{5}}{x^{5}}\right)=\left(\frac{x}{x}\right)^{5}=1^{5}=1
$$

but he didn't do so. WHY?

There is a simple answer, although it took us a long time to understand it. The issue has to do with Nelson's beliefs and orientations about teaching. One of Nelson's central beliefs about teaching - the belief that the ideas you discuss must be generated by the students - shaped what knowledge he did and did not use.

In the first example above (reducing the fraction $x^{3} y^{7} / x^{2} y^{6}$ ), a student said he had subtracted. The fact that the student mentioned subtraction gave Nelson "permission" to explain, which he did: "OK. You looked at the $x$ 's and you subtracted 3 minus 2. That gave you $x$ to the first. And then you looked at the $y$ 's and said 7 minus 6 , gives you $y$ to the first."

But in the case of example (c), $x^{5} / x^{5}$, he was stymied—when he pointed to the

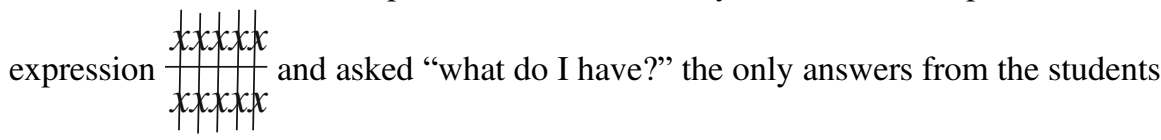
were "zero," "zip," "nada," and "nothing." Nobody said "1." And because of his belief that he had to "build on" what students say, Nelson felt he could not proceed with the explanation. Only later, when he mis-heard what a student said, was he able to finish up his explanation.

[Note: This brief explanation may or may not seem convincing. I note that full detail is given in the book, and that Nelson was part of the team that analyzed his videotape. So there is strong evidence that the claims I make here are justified.]

\section{Second Teaching Example, Jim Minstrell}

Here too I provide just a very brief description.

Jim Minstrell is an award-winning teacher who is very thoughtful about his teaching. It is the beginning of the school year, and he is teaching an introductory 
lesson that involves the use of mean, median, and mode. But, the main point of the lesson is that Minstrell wants the students to see that such formulas need to be used sensibly.

The previous day eight students measured the width of a table. They obtained these values:

$$
106.8 ; 107.0 ; 107.0 ; 107.5 ; 107.0 ; 107.0 ; 106.5 ; 106.0 \mathrm{~cm} \text {. }
$$

Minstrell wants the students to discuss the "best number" to represent the width of the table. His plan is for the lesson to have three parts:

1. Which numbers (all or some?) should they use?

2. How should they combine them?

3. With what precision should they report the answer?

Minstrell gave us a tape of the lesson, which we analyzed. The analysis proceeded in stages. We decomposed the lesson into smaller and smaller "episodes," noting for each episode which goals were present, and observing how transitions corresponded to changes in goals. In this way, we decomposed the entire lessonstarting with the lesson as a whole, and ultimately characterizing what happened on a line-by-line basis. See Figs. 2 and 3 (next pages) for an example of analytic detail. Figure 2 shows the whole lesson, and then breaks it into major episodes (lesson

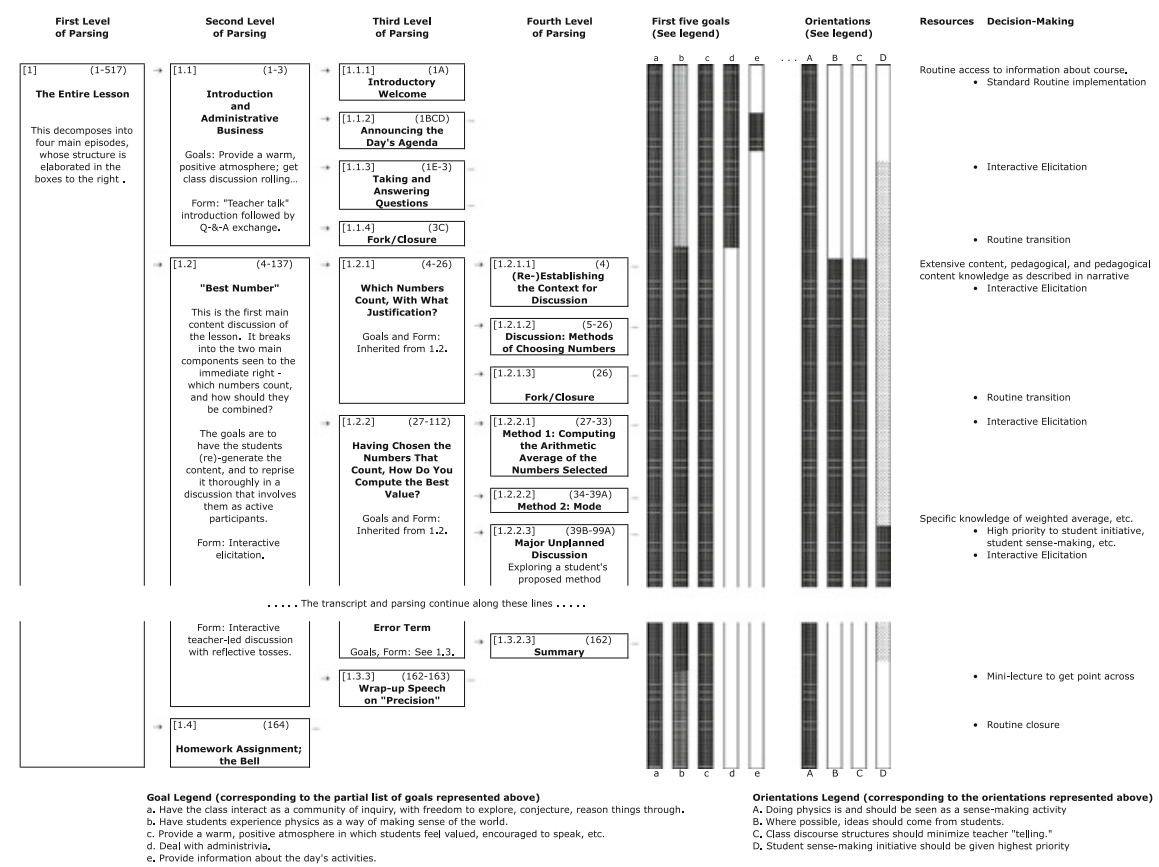

Fig. 2 A "top level" view of Minstrell's lesson, "unfolding" in levels of detail. (With permission, from Schoenfeld 2010, pp. 96-97) 

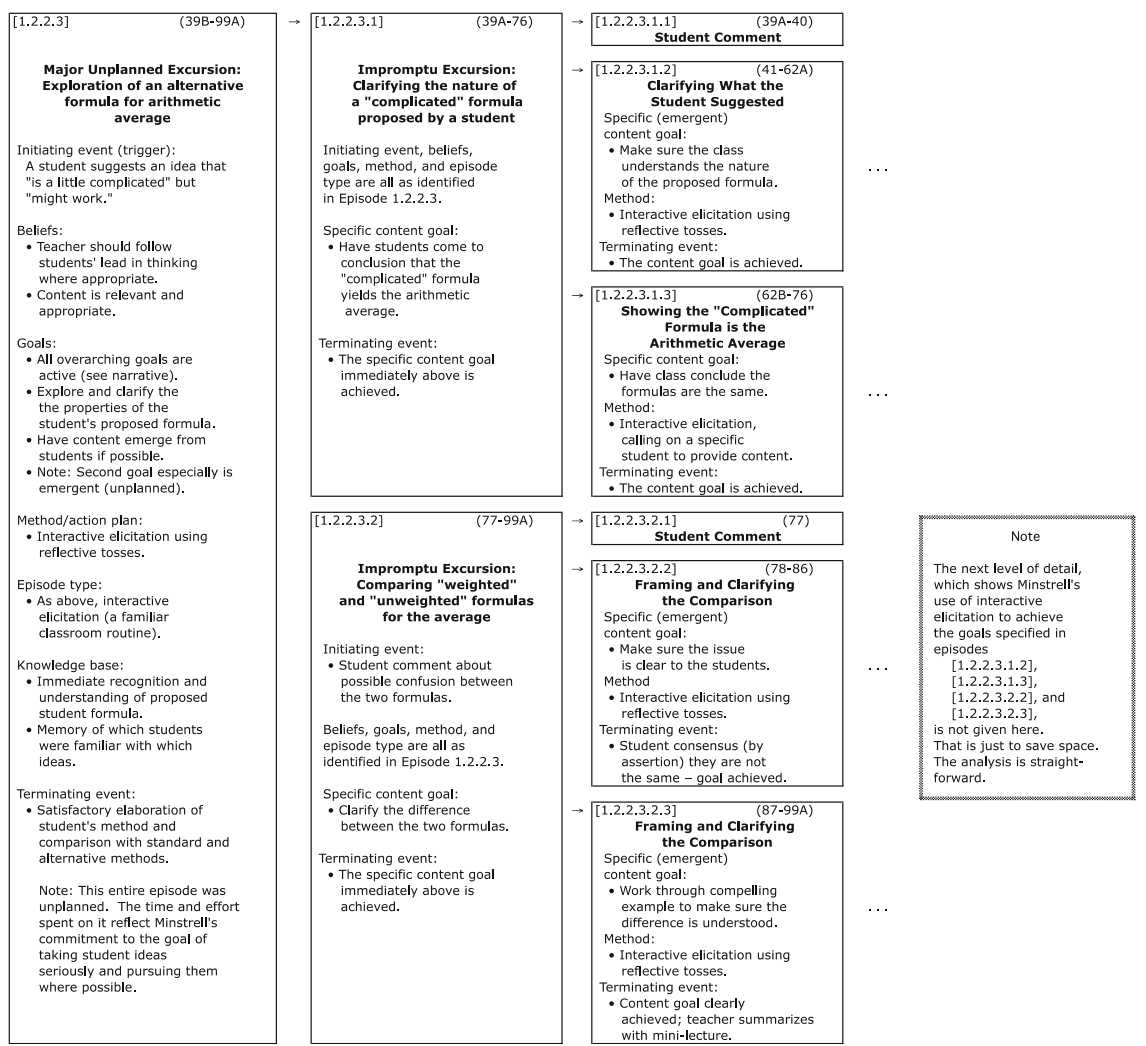

Fig. 3 A more fine-grained parsing of Episode [1.2.2.3]. (From Schoenfeld 2010, pp. 116-117, with permission)

segments), each of which has its own internal structure. Most of the lesson was very simple to analyze in this way.

Minstrell has a flexible "script" for each part of the lesson:

- He will raise the issue;

- He will ask the class for a suggestion;

- He will clarify and pursue the student suggestion by asking questions, inserting some content if necessary.

Once the suggestion has been worked through, he will ask for more suggestions. When students run out of ideas, he may inject more ideas, or move to the next part of the lesson.

In this way, the lesson unfolds naturally, and it is easy to "capture" it-see Fig. 2 for a "top level" summary of how the lesson unfolded. The episodes in the second and third columns, which correspond to an analysis of the lesson as taught, show that Minstrell did cover the big topics as planned. 
A line-by-line analysis (see Schoenfeld 1998, 2010) shows that when Minstrell was dealing with expected subject matter, he followed the "script" described above very closely. So, it is easy to model Minstrell's behavior when he is on familiar ground.

But what about unusual events? Remember the data: The eight values the students had obtained for the width of the table were

$106.8 ; 107.0 ; 107.0 ; 107.5 ; 107.0 ; 107.0 ; 106.5 ; 106.0 \mathrm{~cm}$.

As the lesson unfolded, Minstrell asked the students about "a way of getting the best value." (see box 1.2.2 in the third column of Fig. 2.) As the class proceeded, one student mentioned the idea of using the "average" and, when asked by Minstrell, provided a definition. (Box 1.2.2.1 in the fourth column of Fig. 2.) Another student mentioned mode (Box 1.2.2.2). Then, a student said:

This is a little complicated but I mean it might work. If you see that 107 shows up 4 times, you give it a coefficient of 4 , and then 107.5 only shows up one time, you give it a coefficient of one, you add all those up and then you divide by the number of coefficients you have.

This is an unexpected comment, which does not fit directly with Minstrell's flexible script. The question is, can we say what Minstrell would do when something unexpected, like this, arises in the middle of his lesson?

Before proceeding, I want to point out that there is a wide range of responses, which teachers might produce. I have seen responses like all of the following:

That's a very interesting question. I'll talk to you about it after class.

Excellent question. I need to get through today's plans so you can do tonight's assigned homework, but I'll discuss it tomorrow.

That's neat. What you've just described is known as the 'weighted average.' Let me briefly explain how you can work with that...

Let me write that up as a formula and see what folks think of it.

Let's make sure we all understand what you've suggested, and then explore it.

So, teachers might do very different things. Is it possible to know what Minstrell will do? According to our model of Minstrell, (1) His fundamental orientation toward teaching is that physics is a sense-making activity and that students should experience it as such; (2) One of his major goals is to support inquiry and to honor student attempts at figuring things out; (3) His resource base includes favored techniques such as "reflective tosses"-asking questions that get students to explain/elaborate on what they said.

Thus, the model predicts that he will pursue the last option-making sure that the students understand the issue that the student has raised (including the ambiguity about how you add the coefficients; do you divide by 5 or 8 ?) and pursuing it. He will do so by asking the students questions and working with the ideas they produce. 
This is, in fact, what Minstrell did. Figure 3 shows how that segment of the lesson evolved. It is an elaboration of Box 1.2.2.3 in Fig. 2.

As noted above, it is possible to model Minstrell's decision. The model shows that, when faced with options such as those listed above, Minstrell is by far most likely to pursue the one I have indicated. The computations take about seven pages of text, so I will spare you the detail! More generally:

We have found that we were able to capture Minstrell's routine decision-making, on a line-by-line basis, by characterizing his knowledge/resources and modeling them as described in Fig. 1, "How Things Work;" and,

We were able to model Minstrell's non-routine decision-making using a form of subjective expected value computation, where we considered the various alternatives and looked at how consistent they were with Minstrell's beliefs and values (his orientations).

In summary, we were able to model every decision Minstrell made during the hour-long class.

\section{Third Teaching Example, Deborah Ball}

Some years ago, at a meeting, Deborah Ball showed a video of a third grade classroom lesson she had taught. The lesson was amazing - and it was controversial. In it,

- Third graders argued on solid mathematical grounds;

- The discussion agenda evolved as a function of classroom conversations;

- The teacher seemed at times to play a negligible role, and she made at least one decision that people said was not sensible.

In addition, I had little or no intuition about what happened. Thus, this was a perfect tape to study! There were major differences from cases 1 and 2:

- the students were third graders instead of high school students;

- psychological (developmental) issues differed because of the children's age;

- the "control structure" for the classroom was much more "organic";

- the teacher played a less obvious "directing" role.

The question was, could I model what happened in this lesson? If so, then the theory covered an extremely wide range of examples, which would comprise compelling evidence of its general validity. If not, then I would understand the limits of the theory. (Perhaps, for example, it would only apply to teacher-directed lessons at the high school level.)

Here is what happened during the lesson. Ball's third grade class had been studying combinations of integers, and they had been thinking about the fact that, for example, the sum of two even numbers always seemed to be even. The previous 
day Ball's students had met with some 4th graders, to discuss the properties of even numbers, odd numbers, and zero. Ball had wanted her students to see that these were complex issues and that even the "big" fourth graders were struggling with them. The day after the meeting (the day of this lesson), Ball started the class by asking what the students thought about the meeting:

- How do they think about that experience?

- How do they think about their own thinking and learning?

Ball had students come up to the board to discuss "what they learned from the meeting." The discussion (a transcript of which is given in full in Schoenfeld 2008, 2010) covered a lot of territory, with Ball seemingly playing a small role as students argued about the properties of zero (is it even? odd? "special"?). For the most part, Ball kept her students focused on the "meta-level" question: what did they learn about their own thinking from the meeting with the fourth graders the previous day?

But then, after a student made a comment, Ball interrupted him to ask a mathematical question about the student's understanding. This question, which took almost 3 min to resolve, completely disrupted the flow of the lesson. Many people, when watching the tape of the lesson, call that decision a "mistake." How could Ball, who is a very careful, thoughtful, and experienced teacher, do such a thing? If the decision was arbitrary or capricious in some way, that is a problem for the theory. If highly experienced teachers make arbitrary decisions, it would be impossible to model teachers' decision making in general.

In sum, this part of the lesson seems to unfold without Ball playing a directive role in its development - and she made an unusual decision to interrupt the flow of conversation. Can this be modeled? The answer is yes. A fine-grained analysis reveals that Ball has a "debriefing routine" that consists of asking questions and fleshing out answers. That routine is given in Fig. 4.

In fact, Ball uses that routine five times in the first 6 min of class. Moreover, once you understand Ball's plans for the lesson, her unexpected decision-what has been called her "mistake" by some — can be seen as entirely reasonable and consistent with her agenda. This has been modeled in great detail. For the full analysis, see Schoenfeld 2010; for an analytic diagram showing the full analysis, download Appendix E from my web page, http://www-gse.berkeley.edu/faculty/AHSchoenfeld/AHSchoenfeld. html.

To sum things up: As in the two previous cases, (1) We were able to model Ball's routine decision-making, on a line-by-line basis, by characterizing her knowledge/resources and modeling them as described in Fig. 1. (2) We were able to model Ball's non-routine decision-making as a form of subjective expected value computation.

In short, we were able to model every move Ball made during the lesson segment. 


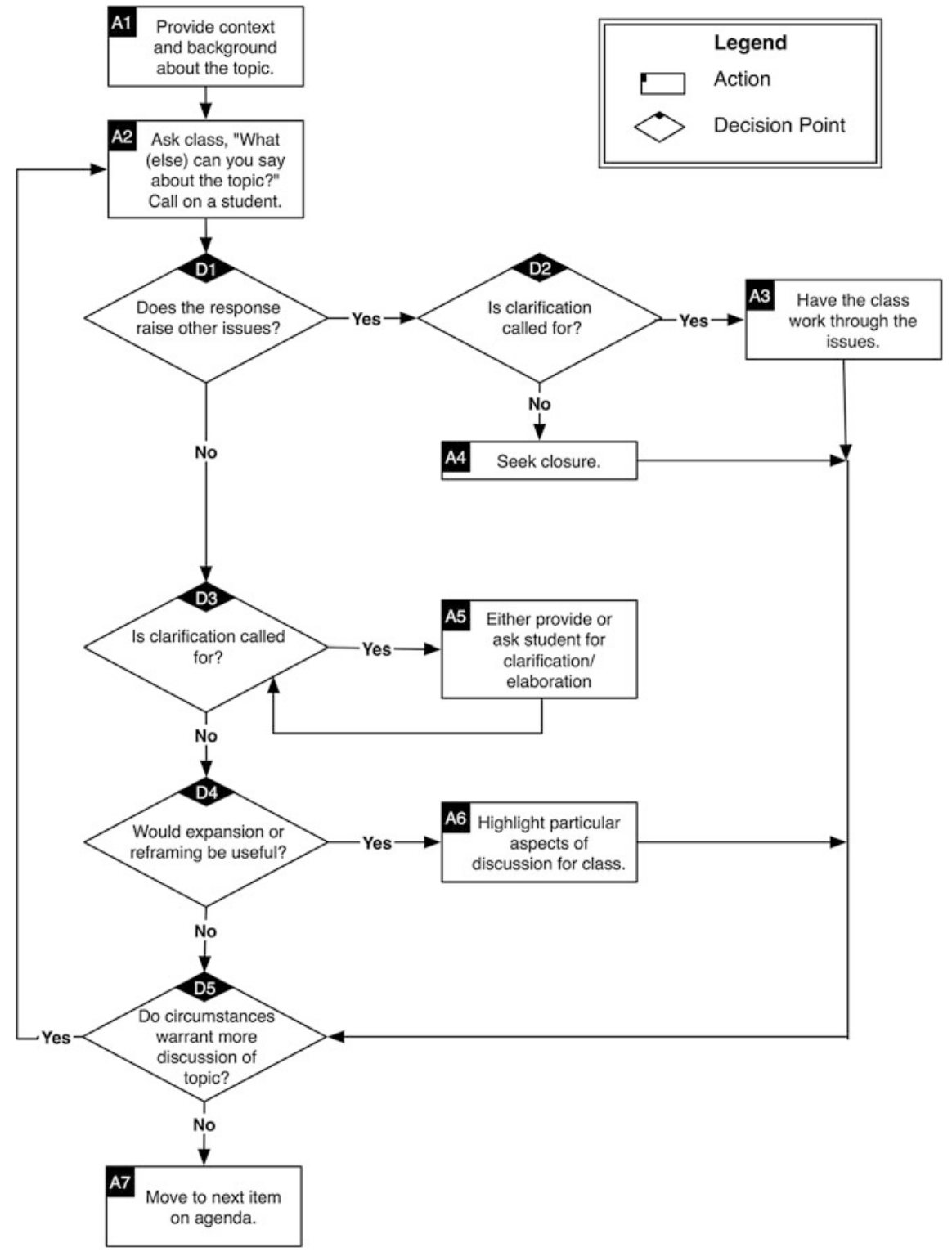

Fig. 4 A flexible, interruptible routine for discussing a topic. (From Schoenfeld 2010, p. 129, with permission) 


\section{Yet More Examples}

\section{Making Breakfast (or Any Other Meal)}

If you look at Fig. 1, you can see that it would be easy to model decision-making during cooking. Usually we have fixed routines for cooking familiar meals. And if something changes (for example, when my daughter asks me to make a fancy breakfast), that calls for a "non-routine" decision, which can also be modeled. Readers might enjoy creating models of their own cooking practices and decision making.

\section{Routine Medical Diagnosis and Practice}

To see if my ideas worked outside of the classroom, I asked my doctor if I could tape and analyze one of my office visits with her. She said yes; an analysis of our conversation is given in How We Think. The conversation was easy to model, because the doctor follows a straightforward (and flexible) script. Modeling a twoperson interaction is a lot easier than modeling a classroom; it is more like modeling a tutoring interaction. When the person being modeled (in this case, the doctor) only has to pay attention to one other person (instead of the 30 children a teacher has to pay attention to), decision-making is comparatively simple - and simple to model.

I should also note that there is a very large artificial intelligence literature on modeling doctors' decision making-there are computer programs that make diagnoses, etc. (The field is well established: see, e.g., Clancey and Shortliffe 1984). So, the idea that it is possible to capture doctors' routine decision making is not new. More recent, and also consistent with my emphasis on beliefs as shaping behavior, there are studies (e.g., Groopman 2007) of how doctors' stereotypes (beliefs and orientations) regarding patient behavior lead them to miss what should be straightforward diagnoses.

\section{Discussion}

The approach I have outlined in this paper "covers" routine and non-routine problem solving, routine and non-routine teaching, cooking, and brain surgeryand every other example of "well practiced," knowledge-based behavior that I can think of. All told, I believe it works pretty well as a theory of "how we think."

Readers have the right to ask, why would someone spend 25 years trying to build and test a theory like this? Here is my response.

First, theory building and testing should be central parts of doing research in mathematics education. That is how we make progress. 
Second, the more we understand something the better we can make it work; when we understand how something skillful is done we can help others do it. This was the idea behind my problem solving work, where an understanding of problem solving helped me to help students become better problem solvers. I believe that a comparably deep understanding of teachers' decision making can be used to help mathematics teachers become more effective.

Third, this approach has the potential to provide tools for describing developmental trajectories of teachers. Beginning teachers, for example, often struggle with issues of classroom "management" - of creating an orderly classroom environment in which their students can learn productively. While teachers are struggling at this, they have little time or attention to devote to some of the more subtle aspects of expert teaching, such as teaching responsively-listening carefully to what their students say, diagnosing what the students understand and misunderstand, and shaping the lesson so that it helps move the students forward mathematically. The more we understand what teachers understand at particular points in their careers, the more we will be able to provide relevant professional development activities for them. An understanding of teachers' developmental trajectories can help us help teachers get better at helping their students learn. (see Chap. 8 of Schoenfeld 2010, for detail.)

Fourth and finally, it's fun! The challenge of understanding human behavior has proved itself to be every bit as interesting and intellectually rewarding as the challenge of understanding mathematics. It has occupied me for the past 35 years, and I look forward to many more years of explorations. Exploring questions of how teachers' understandings develop, and of how and when one can foster the development of mathematics teachers' expertise, are intellectually challenging. Equally important, addressing them can, over the long run, lead to improvements in mathematics teaching and learning.

Open Access This chapter is distributed under the terms of the Creative Commons Attribution Noncommercial License, which permits any noncommercial use, distribution, and reproduction in any medium, provided the original author(s) and source are credited.

\section{References}

Clancey, W. J., \& Shortliffe, E. H. (Eds). (1984). Readings In Medical AI: The First Decade. Reading, Ma: Addison-Wesley.

Groopman, J. (2007). How Doctors Think. Boston: Houghton Mifflin.

Pólya, G. (1945; $2^{\text {nd }}$ edition, 1957). How To Solve It. Princeton: Princeton University Press.

Schoenfeld, A. H. (1985) Mathematical Problem Solving. Orlando, Fl: Academic Press.

Schoenfeld, A. H. (1998). Toward A Theory Of Teaching-In-Context. Issues In Education, 4(1), 1 - 94.

Schoenfeld, A. H. (Ed). (2008) A Study Of Teaching: Multiple Lenses, Multiple Views. Journal For Research In Mathematics Education. Monograph Series \# 14). Reston, Va: National Council Of Teachers Of Mathematics,

Schoenfeld, A. H. (2010). How We Think: A Theory Of Goal-Oriented Decision Making And Its Educational Applications. New York: Routledge.

Schoenfeld, A. H. (in press). How We Think. Revistas Tópicos Educacionais. 